7. Reprod. Fert. (1974) 36, 311-317

\title{
FERTILITY AND REPRODUCTION IN PATIENTS WITH DUODENAL ULCER
}

\author{
Z. KUBÍC̆KOVÁ AND K. T. VESELÝ \\ The Institute of Haematology and Blood Transfusion and the First Research Unit of \\ Internal Medicine of the Institute of Clinical and Experimental Medicine, Prague, \\ Czechoslovakia
}

(Received 13th February 1973)

\begin{abstract}
Summary. A familial study of 424 patients with duodenal ulcers and 1000 controls revealed that the fertility of the patients was reduced by $25 \%$ compared with the healthy controls. This applied irrespective of sex. The lower fertility was due to a higher incidence of childless marriages and a smaller number of children in the families. The incidence of childless marriages was influenced mainly by a positive family-history, i.e. the fact that at least one close relative of the proband suffered from peptic ulceration. The number of children was smaller because the proband suffered from peptic ulceration; this was confirmed in the parental generation.
\end{abstract}

\section{INTRODUCTION}

An adverse effect on reproduction and fertility was recorded in a detailed familial study of a group of patients, in whom the participation of genetic factors in the manifestation of a duodenal ulcer was being investigated (Kubíćková \& Veselý, 1972). The data presented here represent the outcome of a further study based on the observations recorded during the original investigation.

\section{MATERIALS AND METHODS}

A detailed familial analysis was carried out on a group of 424 patients with duodenal ulcers, who were seen in Prague Clinics and Institutes during the period from 1955 to 1968 . In addition to information pertaining to grandparents, data were obtained on three generations: (1) parents of the proband and their siblings; (2) siblings of the proband and children of the parent's siblings; (3) children of the proband, of his siblings and children of his cousins.

The control group comprised 1000 unaffected individuals.

Fertility is closely associated with the age of the proband, and the manifestation of peptic ulcer is positively correlated with the patient's age. Since it is not possible to assess accurately the exact onset of a peptic ulcer, the patient's age at the time of examination was taken as a baseline. 


\section{RESULTS}

The age distribution of patients and unaffected probands is illustrated in Text-fig. 1. The control subjects were younger than the patients suffering from duodenal ulcers. Text-figure 2 illustrates the age distribution of both groups after elimination of unmarried probands. The mean age of the group of patients with duodenal ulcer was 50.41 (S.D. $=13.61$ ) years, but after elimination of the unmarried probands, it was 51.00 (S.D. $=13.3$ ). The mean age of the unaffected probands was 38.67 (S.D. $=12.5$ ) years, but after elimination of the unmarried probands, it was 41.90 (S.D. $=10 \cdot 5$ ).



TExr-Fig. 1. Age distribution of (a) unaffected probands and (b) probands with peptic ulcer.

Problems of fertility were also studied in the proband's parents. Text-figure 3 compares the age distribution of affected probands where at least one parent suffered from peptic ulcer, with those patients whose parents did not have the disease. Text-figure 4 illustrates similar data for unaffected probands. It is apparent that the control and affected probands, whose parents suffered from peptic ulcer, were younger than probands of unaffected parents. The mean age of the probands of affected parents was 35.36 (S.D. $=9.5)$ years, and that of control probands of unaffected parents was 38.92 (S.D. $=12.5$ ). The mean age of affected probands of affected parents was 47.58 (S.D. $=11.5$ ) years, and that of affected probands of unaffected parents was 51.25 (S.D. $=14 \cdot 1$ ) years. 
The difference between the age of the probands of affected and unaffected parents in both groups was approximately 3 years.

If the age of the parents at the time of the child's birth is estimated to be about 25 years and this is added to the lowest age of the probands, the approximate parental age is 60 years. Since the proband is not always the first child, the parental age often exceeds 60 years. The number of their children, most of whom are already married, may therefore be taken as final.

After elimination of unmarried probands, the group of unaffected subjects comprised 815 families, while the group of affected subjects comprised 401



TEXT-pIG. 2. Age distribution of (a) unaffected probands and (b) probands with peptic ulcer, excluding unmarried subjects.

families. The mean number of children per family for the unaffected probands was 1.86 , and the percentage of childless marriages was $11.16 \%$ (men $9.56 \%$, women $13.03 \%$ ).

In the group of affected probands, the mean number of children was 1.38, i.e. 0.48 less than in control probands. There were $21.45 \%$ childless marriages (men $20.00 \%$, women $24.79 \%$ ). This means that in the group of affected probands, there were fewer children and more childless marriages than in the unaffected probands.

From the data on the average number of children of affected and control probands, the selection coefficient in duodenal ulcer was calculated as 0.74 . 
The data on parents in the groups of unaffected and affected probands were similarly analysed, taking into account whether or not the parents suffered from peptic ulcer. The group of affected probands comprised 97 families with 250 children (including probands) where at least one of the parents suffered from peptic ulcer; the average number of children was 2.57 . In the remaining 327 families where both parents were unaffected, there were 993 children, i.e. the average per family was 3.03 . Here too the number of children of affected



Text-pig. 3. Age distribution of probands suffering from duodenal ulcer: (a) patients whose parents did not suffer from peptic ulceration; (b) affected probands where at least one parent suffered from peptic ulceration.

parents was smaller. The selection coefficient was $0 \cdot 84$, i.e. apparently higher than in the generation of probands. The difference can be explained by the fact that, in the parental generation, there are no childless marriages. If the $10 \%$ difference in childlessness between the affected and unaffected probands is included in the calculation, the same selection coefficient of 0.74 is obtained.

The same result was also obtained in the parents of unaffected probands. The first part of the group, where at least one of the parents suffered from peptic ulcer, comprised 72 families with 150 children. There were 2.08 children per family. The second part of the group with unaffected parents comprised 928 
families with 2295 children and there were 2.47 children per family. Again, the selection coefficient was $0 \cdot 84$.

These groups of parents naturally do not comprise unmarried individuals and childless marriages as the probands are being used as a basis. In order to compare the parents with the group of probands, the unmarried and childless subjects were eliminated from the latter group. In the group of affected subjects, there were left 315 families with 555 children, and the average number of children per family was 1.76 . In the group of unaffected subjects, there were

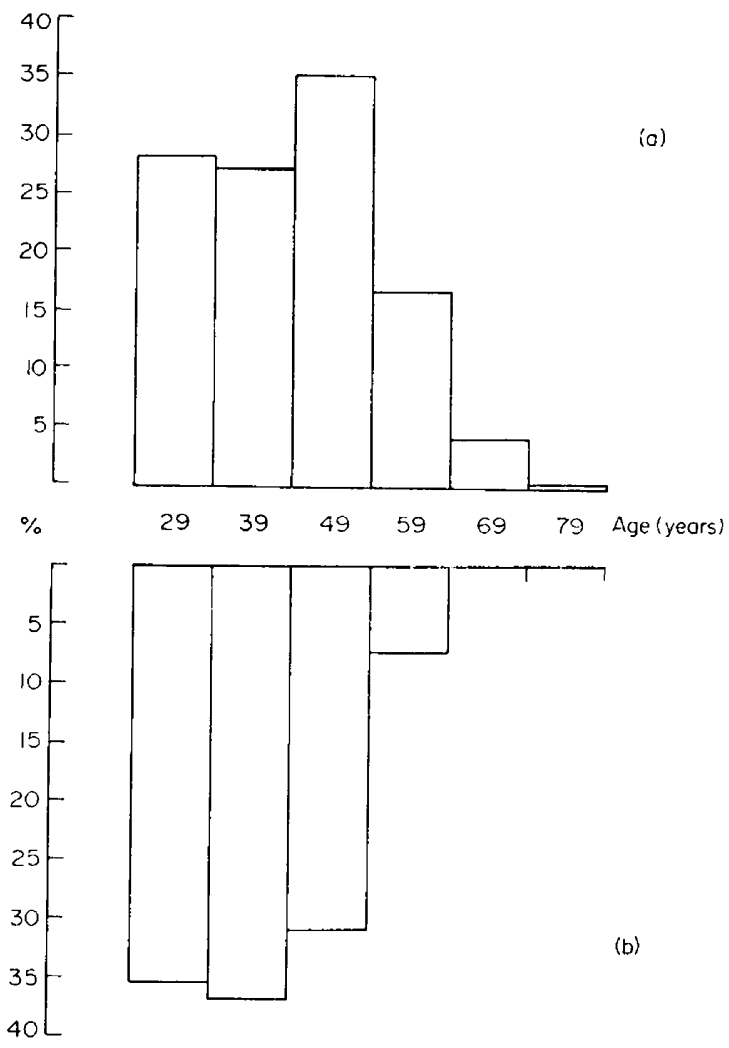

Text-Fig. 4. Age distribution of unaffected probands (controls): (a) probands whose parents did not suffer from peptic ulceration; (b) probands where at least one parent suffered from peptic ulceration.

1516 children in 724 families, and the mean number of children per family was $2 \cdot 09$. The selection coefficient was $0 \cdot 84$, as for their parents.

The fertility of patients with peptic ulceration could also be influenced by a positive family history, i.e. at least one of the proband's relatives suffers from peptic ulcer. Patients who had children were, therefore, classified according to their family history. The 162 patients with a positive family history had 283 children and the mean number per family was $1 \cdot 75$. The 153 patients with a negative family history had 272 children and the mean number per family was $1 \cdot 78$. 
In order to assess the effect of a positive family history on the childlessness of affected probands, single individuals were eliminated from the group of affected probands and the group was subdivided according to the family history. There were 219 families with a positive family history including 57 childless ones, i.e. $26.03 \%$. There were 182 families with a negative family history, including 29 , i.e. $15.93 \%$, childless ones. It was thus shown that a positive family history was manifested by a higher percentage of childless marriages.

\section{DISGUSSION}

The results of the familial study of a group of control subjects and a group of patients with duodenal ulcer have revealed that peptic ulceration has an adverse effect on reproduction. The individuals in the control group were, on average, 10 years younger than those in the affected group. Even without the difference in age, however, we may assume that the unaffected probands are more likely to have further children than the affected probands; this would make the assessed difference between the groups even more marked.

The control group can be taken as a representative sample of the Czech population with regard to its size and also with regard to the assembled data. The mean number of children per family of 1.86 is in keeping with the figures of 1.78 quoted by Vomáčková (1971) for the Czech Socialist Republic (excluding Slovakia) and 1.89 for the whole of Czechoslovakia. Our mean group figure corresponds to that for the Czech Socialist Republic; its slightly higher value may be due to the fact that it is based on data recorded in the 1960 s, i.e. older data than that recorded by Vomáčková. The mean number of children per family has recently shown some decline in Czechoslovakia, and the mean number of children in the parental generation is therefore higher than in the proband generation and reaches its highest value in parents of the oldest affected probands.

The mean number of children per family in the population depends also on the percentage of childless marriages. The figure of $11.16 \%$ in our group of unaffected probands corresponds to the data available for the Czech population as a whole. Cerný (1967) quotes a figure of $10 \%$ for infertile marriages, and Vomáčková (1971) stated that there are $6 \%$ of women with confirmed infertility and $8 \%$ of women whose infertility could not be reliably proved.

The children of parents suffering from peptic ulcer are, on average, 3 years younger than the children of unaffected parents. It is not possible to explain this phenomenon as we do not know the proband's age at the onset of the disease, the age of the proband's parents (or rather of the parent suffering from a peptic ulcer), or the order of the proband in the family. Only these data could confirm our finding and possibly also elucidate its cause.

The selection coefficient in peptic ulceration is 0.74 ; this means that patients with duodenal ulcer, regardless of sex, have a $25 \%$ lower fertility rate compared to the general population. The selection coefficient was also calculated for the affected parents of all probands and a value of 0.84 was obtained. It was obviously lower than in the affected probands because the group of parents did not comprise childless marriages. As the difference in childless marriages 
in our groups of affected and unaffected probands is roughly $10 \%$ (affected $21.45 \%$, unaffected $11.16 \%$ ), it may be expected that by including these $10 \%$ we would obtain the same selection coefficient, i.e. $0 \cdot 74$.

To test this, we eliminated not only unmarried but also childless subjects from the groups of affected and unaffected probands and assessed the selection coefficient. The value was $0 \cdot 84$, corresponding to the value found in the parental groups. This also confirmed that the number of children of peptic ulcer patients was really lower compared with those of unaffected subjects.

In affected parents, it was not always possible to assess reliably whether a duodenal or a gastric ulcer was involved. Despite the fact that in Czechoslovakia, as in the whole of Europe, duodenal ulcer predominates (Veselý, Kubičková \& Dvořáková, 1968), it seems probable that the finding of impaired reproduction is associated with peptic ulcers of all types.

Our results revealed that peptic ulcer reduces the reproductive ability of the individual in the sense that the number of children born to affected probands as well as affected parents is smaller than to unaffected individuals. The finding was supported by the observation that the number of children of patients with peptic ulcer was not influenced (i.e. further reduced) by a positive family history of peptic ulcer.

By contrast, our detailed analysis revealed that childlessness was more frequent in affected probands with a positive family history of peptic ulcer than in affected probands with a negative family history: $26.03 \%$ compared to $15.93 \%$, respectively. A positive family history has thus been shown to participate in the higher rate of childless marriages for subjects suffering from peptic ulcer. At the same time, it has no bearing on the number of children who are born. The number is, however, reduced compared to the average for the general population, as a result of the proband's disease.

As peptic ulcer is a disease with a high incidence in the population, the findings of this study would seem to be important, in particular in countries with a low birth rate, and it would be advisable to make use of the findings in genetic counselling and when recommending a therapeutic protective regimen for patients and whole families.

\section{REFERENCES}

Cerný, M. (Ed.) (1967) Lékařská genetika. Monograph. St. zdrav. Nakl., Prague.

Kubíčková, Z. \& VeselÝ, K. T. (1972) The value of investigations of the incidence of peptic ulcer in the families of patients with duodenal ulcer. Fnl med. Genet. 9, 38.

Veselý, K. T., Kubíč́ová, Z. \& Dvởáková, M. (1968) Clinical data and characteristics differentiating types of peptic ulcer. Gut, $9,57$.

Vomáč́ovÁ, O. (1971) Některé otázky reprodukce manželství v CSSR. Populační zprávy, 1, 15. (Information Bulletin on Population Problems). 